\title{
O CABELO DE LELÊ: REFLEXÕES SOBRE EDUCAÇÃO, CULTURA E IDENTIDADE
}

\author{
Agnaldo Mesquita de Lima Junior ${ }^{1}$ \\ Gionara Tauchen $^{2}$
}

\begin{abstract}
Resumo: A partir da obra "Os cabelos de Lelê", o presente trabalho analisa os pressupostos educativos contidos na obra, focando-se no debate sobre a formação e descoberta de identidades e erotização infantil através do matrimônio. A ideia central é mostrar como as diferentes vontades de pedagogia funcionam na condução de sujeitos e como essas diferentes vontades se articulam com a cultura contemporânea, utilizando-se do conceito foucaultiano de governamento. Por fim, a guisa de conclusão acreditamos com este trabalho ter possibilitado uma nova compreensão na forma de percepção dos livros infantis como artefatos culturais de grande importância para o governo da infância, explicitando uma vontade de pedagogia própria voltada principalmente para as relações étnico-raciais, porém atuando também nas relações de gênero.
\end{abstract}

Palavras-chave: Identidade; Cultura; Educação; Governamento.

\section{O CABELO DE LELÊ: REFLEXIONES ACERCA DE LA EDUCACIÓN, CULTURA E IDENTIDAD.}

Resumen: A partir de la obra "Os cabelos de Lelê", el presente trabajo busca reflexionar acerca de los presupuestos educativos contenidos en la obra, con enfoque en el debate sobre la formación y descubierta de identidades y erotización infantil a través del matrimonio. La idea central será presentar como las diferentes voluntades de pedagogía trabajan en la conducción de sujetos, utilizando-se así del concepto foucaultiano de gobiernamiento y, además de eso, presentar como las diferentes voluntades se articulan con las culturas a su vuelta. Por fin, a guisa de conclusión, creemos con este trabajo tener posibilitado una nueva comprensión en la forma de percepción de los libros infantiles como artefactos culturales de gran importancia para el gobierno de la infancia, explicitando una voluntad de pedagogía propia, dirigida principalmiente a las relaciones étnicoraciales, actuando también en las relaciones de género. Palabras-clave: Identidad; Cultura; Educación; Gobiernamiento

\footnotetext{
${ }^{1}$ Mestrando em Educação pela Universidade Federal do Rio Grande (FURG). Pesquisador da Rede de Estudos e Pesquisas em Educação Superior (REPES).

${ }^{2}$ Doutora em Educação pela Pontifícia Universidade Católica do Rio Grande do Sul (PUCRS); Mestre em Educação pela Universidade Federal de Santa Maria (UFSM). Líder da Rede de Estudos e Pesquisas em Educação Superior (REPES).
} 


\section{Educação, cultura e livros didáticos: caminhos que se cruzam}

Percebe-se, atualmente, uma grande variedade de materiais didáticos com propostas educativas que se constituem como importantes instrumentos educativos para a infância. Nesse escopo, destacam-se os livros de literatura infantil como obras de suporte para estratégias de educação da infância. Essas obras têm íntimas relações com a(s) cultura(s) na(s) qual(is) encontram-se inseridos. E, mais que isso, são produtos resultantes da interação entre as realidades culturais e as concepções pedagógicas . Nesse sentido, Camozzato (2014) afirma que a pedagogia surge na atualidade como eixo articulador entre a cultura e as aprendizagens. Isso porque Eagleton (2000) afirma sobre a cultura que:

\footnotetext{
Não nascemos seres culturais, nem seres naturais auto-suficientes, mas criaturas cuja inescapável natureza física é tal que a cultura é uma condição de sobrevivência. A cultura é o suplemento que preenche um vazio no cerne da nossa natureza e as nossas necessidades materiais são depois reconduzidas nos seus termos. (p.129)
}

Assim, observa-se que através da cultura, as pedagogias intercedem e organizam as relações educativas. Costa, Hessel e Sommer (2003) afirmam que "a cultura não pode mais ser concebida como acumulação de saberes ou processo estético, intelectual ou espiritual" (p. 38). Do contrário, ainda na ideia dos autores, emerge a necessidade de um estudo aprofundado da cultura, levando-se em consideração suas associações com a vida comum e social da atualidade. Nesse contexto, todos os artefatos produzidos e circulantes nas arenas culturais, são considerados artefatos culturais.

Voltando às obras didáticas, os livros de literatura infantil, tem por obrigatoriedade do gênero, preceitos educativos, justificando assim, uma 'vontade de pedagogia' através de uma vontade de condução dos sujeitos, vinculado ao seu governamento, conforme analisado por Camozzato e Costa (2013). Cabe ressaltar, aqui, a ideia de governamento como indução, condução, guia e direcionamento tanto de si para si, como de si para outros, conforme explicitado em Bambi (2002), ou nas palavras de Foucault (1995), como forma de "conduzir condutas e ord enar probabilidades" (p.244).

Para explicitar algumas modulações dessa 'vontade de pedagogia'(CAMOZZATO E COSTA, 2013), utilizaremos como objeto de análise neste trabalho o livro infantil " $O$ cabelo de Lelê,", A presente obra retrata a história do personagem 'Lelê' e sua experiência

\footnotetext{
3 O livro o "O Cabelo de Lelê", de autoria de Valéria Belém, com ilustrações de Adriana Mendonça, publicado pela Companhia Editora Nacional, no ano de 2007.
} 
de não aceitação de uma identidade étnico/estético-cultural (representada na obra pelo seu cabelo) até a compreensão de suas raízes e do funcionamento de sua cultura.

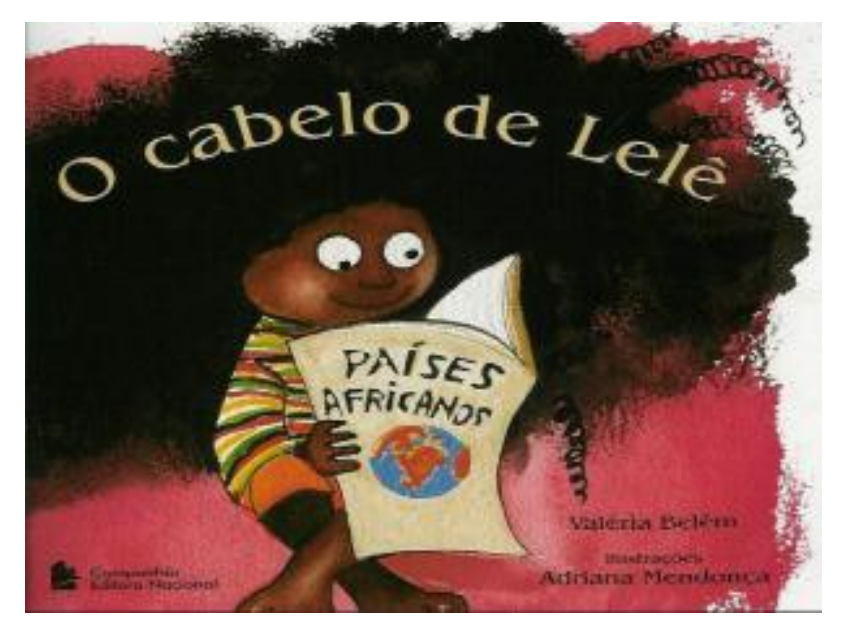

Imagem 1 - Capa do livro "O cabelo de Lelê"

A obra contempla as matrizes afro-brasileiras, explicitando conforme Lima Junior e Freitas (2015), um crescimento da importância da conscientização sobre esta temática desde a infância. Porém, essas vontades provenientes dos livros infantis, de atuar sobre as infâncias, ademais de propor reflexões, como mostrar-se-á na obra analisada, também produzem outros efeitos: ao passo que educam, educação aqui entendida conforme proposto por Camozzato e Costa (2013), como forma de introdução dos sujeitos no mundo e uma inserção na sociedade vigente, para uma realidade como a do respeito e promoção à igualdade étnico racial, acabam, também, por outro lado, por deseducar e promover ideais que, neste caso, podem ser percebidas como machistas e de submissão feminina. Ambas as visões serão propostas e ressaltadas no decorrer do trabalho, buscando uma compreensão dessas formas de pedagogia e suas relações com a cultura a seu redor.

Cabe ressaltar ainda que a obra de literatura infantil, como artefato de análise cultural, compõe também um artefato pedagógico, uma vez que conforme Costa (2010),

[...] seria difícil pensar-se em alguma pedagogia que não seja produzida pela cultura, sendo, portanto, culturais todas as pedagogias - o conceito tem sido útil para referirmo-nos àquelas práticas culturais extraescolares que participam de forma incisiva na constituição de sujeitos. (p.137)

Como proposta de uma crescente 'vontade de pedagogia' as obras de literatura infantil se colocam, enquanto artefatos culturais de educação de sujeitos para o convívio em sociedade, como facilitadores de uma compreensão de si e da cultura. Sobre este tema, Camozzato (2015) afirma que: 
[...] a pedagogia está implicada nos saberes e práticas disponibilizados para que as pessoas possam agir sobre si mesmas e sobre os outros. Pois bem, em uma sociedade múltipla, em que as lutas pela significação são incessantes, a pedagogia também precisa funcionar tendo em conta essa estratégia de tradução das culturas para poder compreender, interagir e atuar sobre essa mesma pluralidade. (p.516)

Nesse sentido, o livro sugere uma forma de valorização de suas características étnico-raciais, através da abordagem do personagem 'Lelê'. Tal atitude também promove uma "cultura de si”, que segundo caracterizado por Foucault (2009a), é a forma “[...] na qual são intensificadas e valorizadas as relações de si para consigo" (FOUCAULT, 2009a, p.49). Assim, seguindo o proposto por Icle (2007), defende-se uma cultura de si, pois “[...] longe de ser um exercício narcisista consiste numa prática social para melhor viver" (ICLE, 2007, p. 49).

De forma geral, este trabalho surge com o objetivo central de analisar os pressupostos educativos do artefato cultural acima descrito, promovendo reflexões sobre a formação de identidades étnico/estético-culturais das infâncias negras, bem como as possibilidades de interpretações possíveis da leitura desta obra. Também será analisado um viés possível de leitura da erotização infantil posta na obra, a partir de imagens que remetam ao matrimonio na obra em debate. Para isso, será trabalhado o desvelamento do discurso a partir das ideias de Foucault (2008), uma vez que

[...] por mais que o enunciado não seja oculto, nem por isso é visível; ele não se oferece à percepção como portador 126 Michel Foucault manifesto de seus limites e caracteres. É necessária uma certa conversão do olhar e da atitude para poder reconhecê-lo e considerá-lo em si mesmo. Talvez ele seja tão conhecido que se esconde sem cessar; talvez seja como essas transparências familiares que, apesar de nada esconderem em sua espessura, não são apresentadas com clareza total. O nível enunciativo se esboça em sua própria proximidade (FOUCAULT, 2008, p.125-127).

Partindo deste preceito, busca-se ainda desvelar o que está implícito no discurso da obra analisada, afim de revelar sua atuação a partir da circulação de conhecimentos a que se propõe. Uma vez que um enunciado participa de um conjunto de ações e discursos, ele atua de modo fundamental na produção e disputas de poder pois,

[...] não há enunciado em geral, enunciado livre, neutro e independente; mas sempre um enunciado fazendo parte de uma série ou de um conjunto, desempenhando um papel no meio dos outros, neles se apoiando e deles se distinguindo: ele se integra sempre em um jogo enunciativo, onde tem sua participação, por ligeira e ínfima que seja (FOUCAULT, 2008, p.112). 
Merece ser ressaltado ainda, conforme sugestionado por Fischer (2001) ao discorrer sobre livros de educação infantil, que a medida que os artefatos são produções históricopolíticas, seu discurso é então composto de palavras com o mesmo sentido, sendo então constitutivo de práticas que vêm a modificar os modos de viver, agir e pensar na sociedade. Foucault (2008) ressalta que as diferentes formas de significar dos discursos, devem ser percebidas e analisadas globalmente a seu tempo e seu conjunto, e não divididas e separadas de seu contexto real. Ou em outras palavras: "Quando se descreve a formação dos objetos de um discurso, tenta-se identificar os relacionamentos que caracterizam uma prática discursiva e não se determina uma organização léxica nem as escansões de um campo semântico" (FOUCAULT, 2008, p. 54). Em função disso, as análises realizadas buscam compreender as interrelações do artefato com o contexto sociohistórico a que está submetido.

\section{A educação para a igualdade racial: uma visão possível}

Inicialmente na obra, o personagem Lelê sente-se esteticamente inferior pela constituição de seus cabelos. Sobre esse sentimento de inferioridade, pode-se compreender através de Foucault (2002), o poder exercido sobre o corpo dos indivíduos. Prudente (2016) destaca que essa opressão imagética decorre dos interesses euro ocidentais que consistem, sobretudo "[...] na fragmentação da dignidade do ibero-ásio-afro-ameríndio, aviltando sua imagem com o inegável estereótipo de inferioridade” (p.434). Em uma sociedade em que, popularmente, se tem como difundida a qualificação de características predominantemente caucasianas, os sentimentos do personagem têm forte ligação com o poder imposto. Weschenfelder (2012) defende que, historicamente, o negro, no Brasil, foi percebido de forma negativa e subjugado pela ótica moderna. Assim, o descontentamento do personagem Lelê com sua aparência é reflexo do sentimento de milhares de crianças negras brasileiras. Isso se dá, também, por uma hegemonia do padrão estereotipado branco, em que se cristalizam as identidades e desvaloriza-se o que porventura fugir a esta regra. Inicialmente, Lelê sugere descontentamento com seu cabelo e tenta arrumá-lo para que possa seguir o padrão socialmente valorizado. Tal comportamento é ratificado por Nyamien (2008), ao afirmar que esse sentimento sentido pelo personagem faz parte de uma estratégia socialmente utilizada por uma maioria étnica:

As representações que se constroem acerca da identidade, quando tende a definir o outro a partir dos padrões e interesses dominantes, tendem a 
cristalizar estereótipos sobre esse outro, fazendo-os parecer verdadeiros. Dessa forma é construída a ideologia racial de legitimidade e superioridade da etnia branca em contraposição a ilegitimidade e inferioridade da etnia negra. Isso leva o grupo dominante a utilizar estratégias de diferenciar-se dos outros e diferenciar os outros de si, para assegurar a sua legitimidade e dessa forma determinar as identidades. (NYAMIEN, 2008, p.03)

Por outro prisma, Foucault (2002) afirma que a identidade se compõe nas relações estabelecidas pelo próprio sujeito e as forças de poder que exercem pressão sobre seus corpos, atitudes e desejos. Neste primeiro momento, Lelê encontrava-se em disputa entre as força hegemônicas que buscavam um apagamento de sua identidade e a manutenção de sua identidade étnico/estético-culturais.

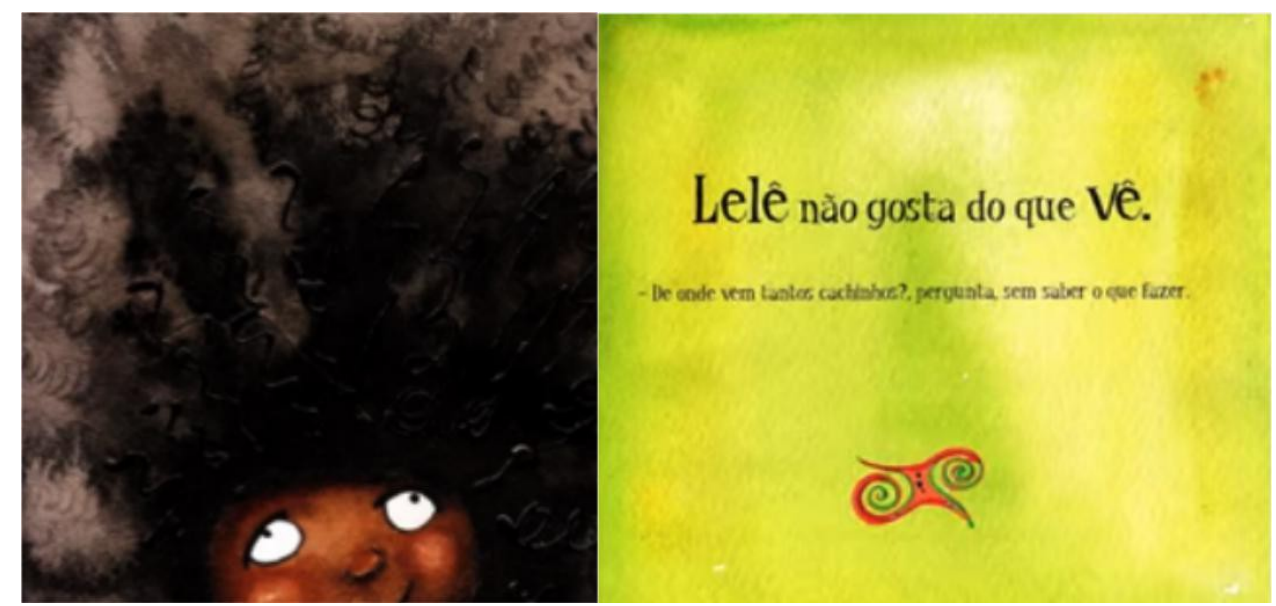

Imagens 2 e 3 - Desapontamento de Lelê com sua aparência

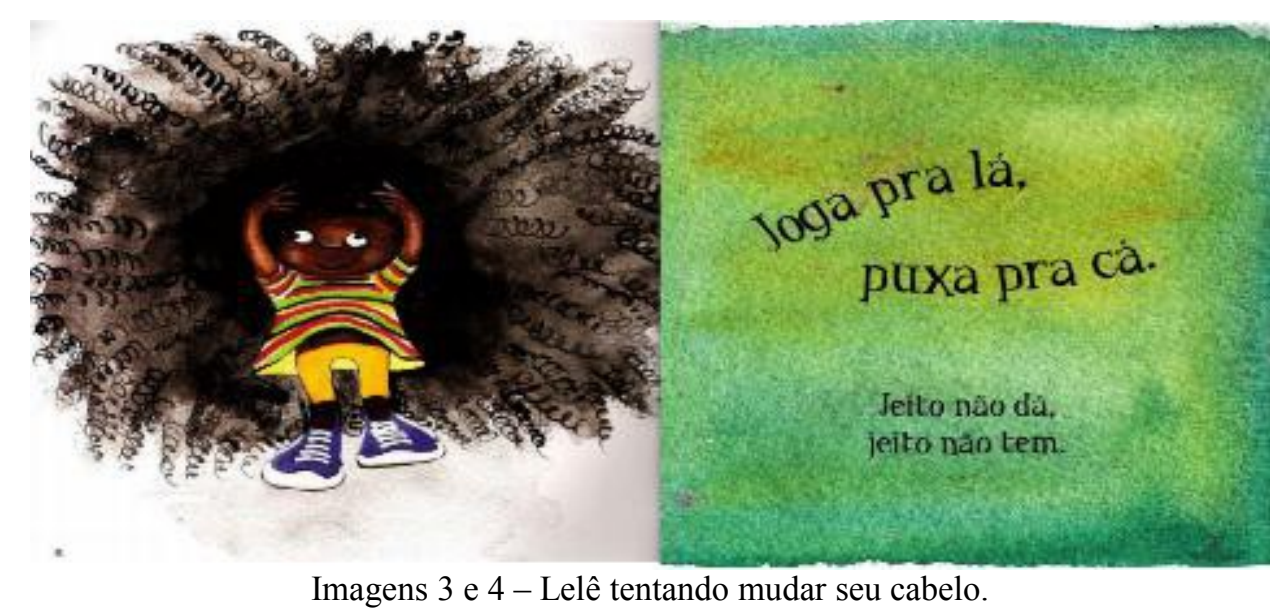

Porém, na obra, é sugerida uma visão oposta à essa desvalorização. Inicialmente através da dúvida sobre a origem de seu cabelo, e posteriormente buscando analisar suas 
raízes, Lelê tenta analisar sua identidade e compreendê-la. Sobre a identidade, Weschenfelder (2012) afirma que:

Ao falarmos de identidade, estamos sempre afirmando o que somos, aquilo que nos define. Em outras palavras, tratar de identidade é aprisionar algo que nos escapa a todo o momento, é procurar definir uma estrutura que está constantemente em mutação e permeada pelas relações de poder. (WESCHENFELDER, 2012, p.26)

Assim, o personagem Lelê encontra um caminho para entender de onde surgiu seu cabelo. E assim, conforme verificável na imagem abaixo, resolve buscar nos livros a compreensão de suas raízes.

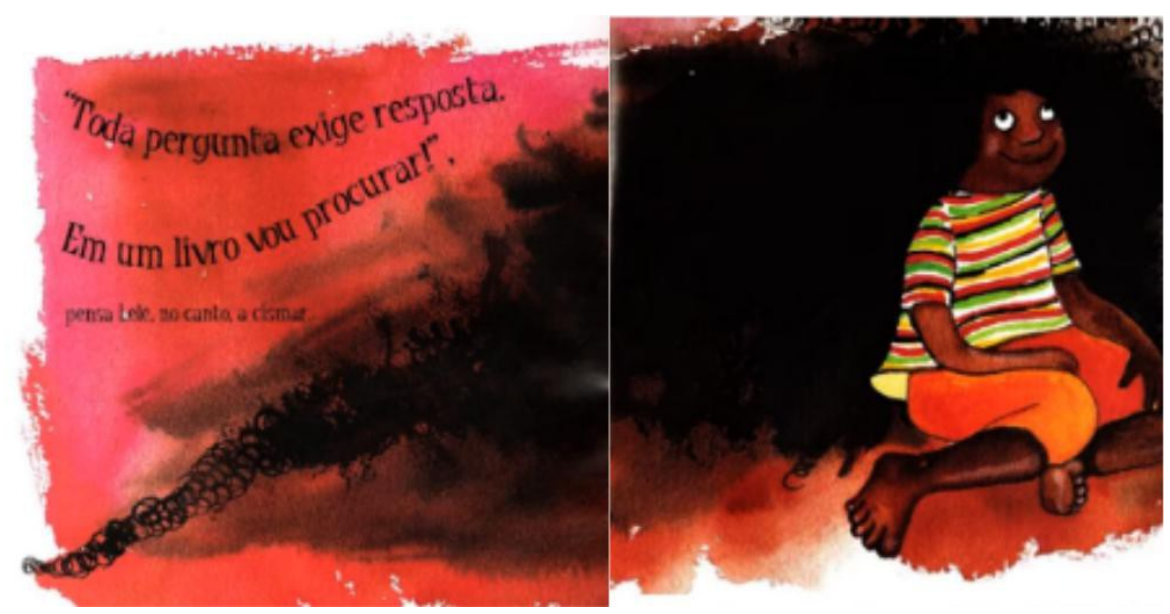

Imagens 5 e 6 - Lelê resolve investigar sobre a origem de seu cabelo

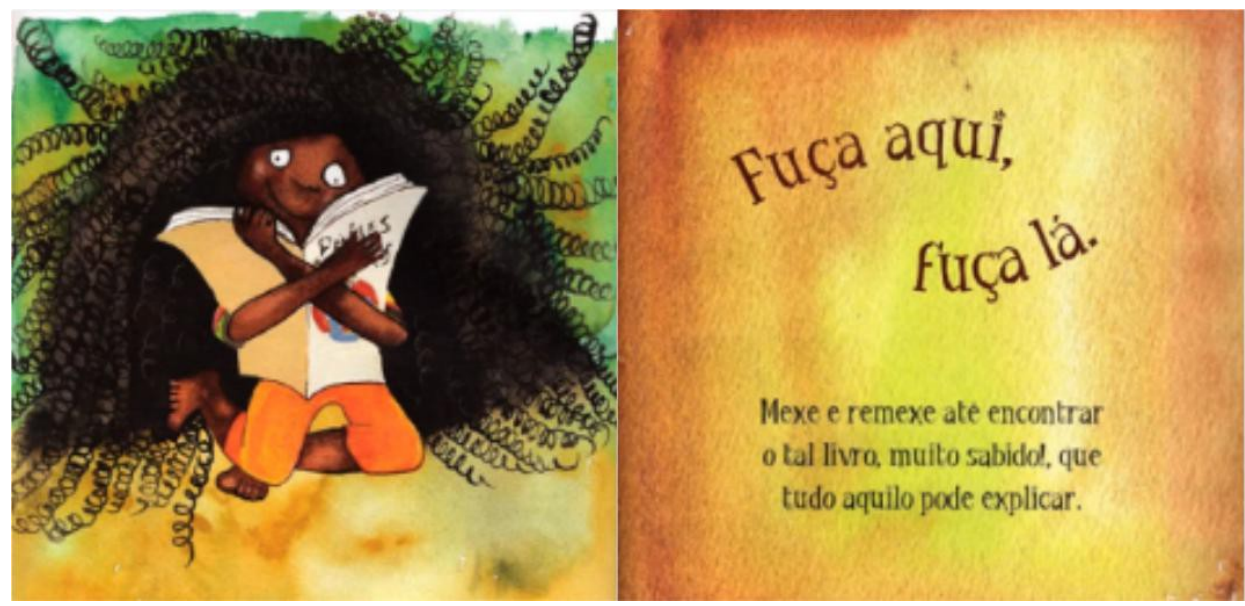

Imagens 7 e 8 - Lelê resolve investigar sobre a origem de seu cabelo

Este ato mostra uma intensa necessidade de agir sobre as infâncias leitoras desses livros, uma vez que assim será possível educá-las. Assim, Camozzato (2015) afirma que '[...] a pedagogia opera nesse limiar entre as maneiras de conduzir os indivíduos aos discursos que sejam socialmente considerados legítimos no contexto em que está em 
funcionamento. (p.508)". Percebe-se, dessa forma, a condução do texto à formas de pensar que levem seus leitores à pesquisar suas raízes e compreender suas origens, mostrando assim um interesse em legislar a favor da igualdade racial.

Em outro ponto, Gouvêa (2005) aponta as características geralmente atribuídas ao negro nos livros infantis:

Os negros eram destituídos de sua identidade étnico-cultural, reduzida a diferenciações físico-raciais. A possibilidade de tal convivência dava-se por meio do embranquecimento dos personagens negros, do despojamento de sua identidade racial. (GOUVÊA, 2005, p.89)

Neste sentido, o livro expressa potencialidades diferentes do que é geralmente oferecido às crianças leitoras de obras infantis. Mostra assim uma demarcação de espaço dentro da literatura infantil buscando atualizar-se para buscar, conforme dito por Camozzato e Costa (2013) “[...] adentrar os múltiplos âmbitos de nossas existências (p. 23).”.

Convém observar que o pressuposto educativo da obra analisada reflete também em um (re)conhecimento do outro e de si próprio. A partir das ideias foucaultianas, Bambi (2002) afirma que "a prática de uma estética do eu não é nada mais nada menos que as formas pelas quais os indivíduos são produzidos e se produzem enquanto sujeitos" (p. 140). Dessa forma, o conhecimento de suas raízes leva o personagem Lelê à construção de uma identidade própria, permeada por ideais forjados internamente em si, porém com contribuições dos artefatos e da cultura a sua volta.

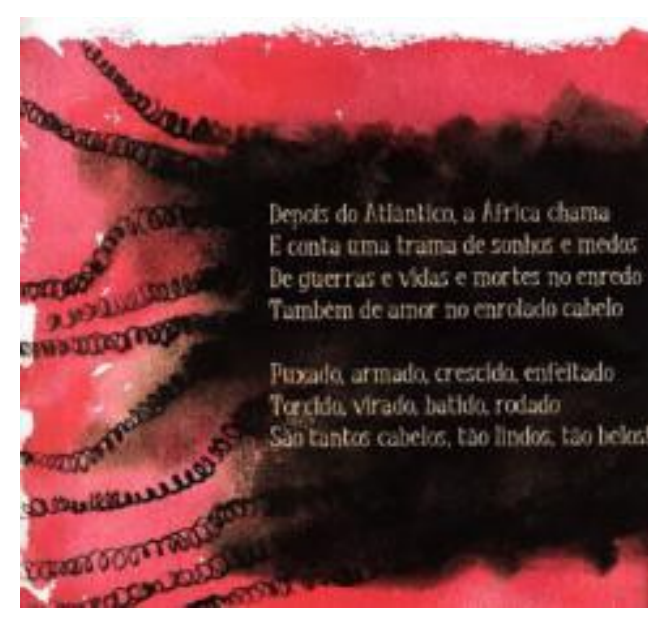

Imagem 9 - Lelê pesquisando sobre sua identidade

O conhecimento de suas raízes propiciou em Lelê o desenvolvimento de uma “cultura de si”. Este conceito, nas palavras de Foucault (2009a) expressa-se no 
[...] preceito segundo o qual convém ocupar-se consigo mesmo é em todo caso um imperativo que circula entre numerosas doutrinas diferentes; ele também tomou a forma de uma atitude, de uma maneira de se comportar, impregnou formas de viver; desenvolveu-se em procedimentos, em práticas e em receitas que eram refletidas, desenvolvidas, aperfeiçoadas e ensinadas; ele constituiu assim uma prática social, dando lugar a relações interindividuais, a trocas e comunicações e até mesmo a instituições; ele proporcionou enfim um certo modo de conhecimento e a elaboração de um saber. (FOUCAULT, 2009a, p. 50)
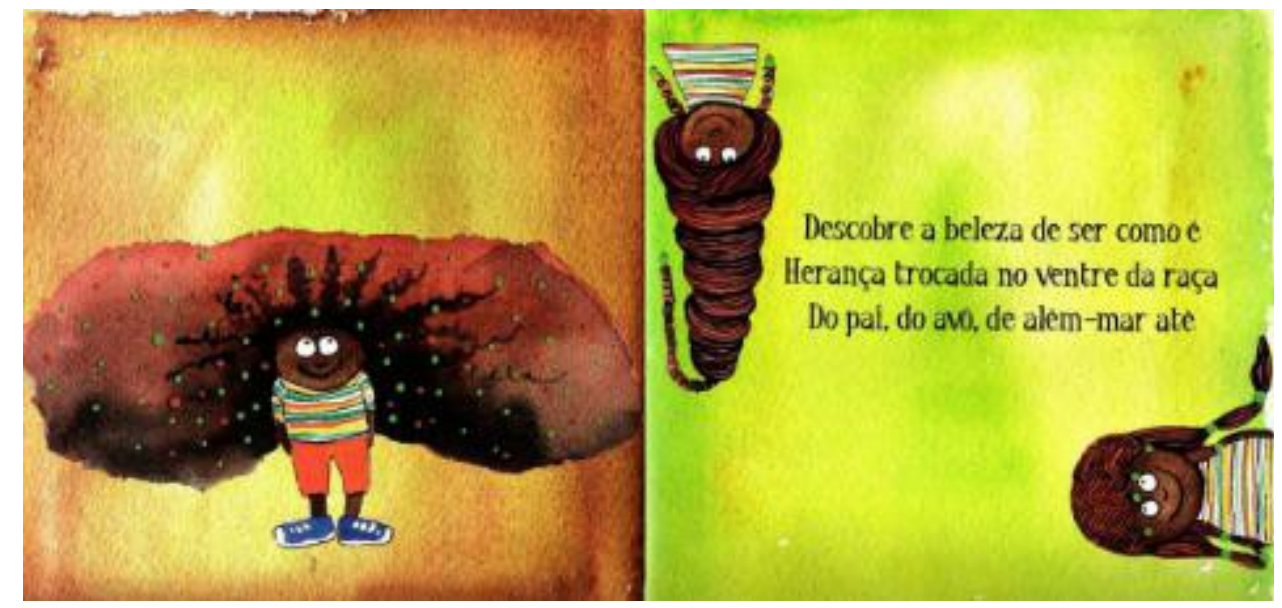

Imagens 10 e 11 - Lelê satisfeito com sua identidade étnico/estético-cultural.

Cabe frisar que, ainda em Foucault (2009a), afirma-se que "[...] não há idade para se ocupar consigo" (FOUCAULT, 2009a, p.544), mostrando que desde a mais tenra idade, quando os processos identitários ainda estão em formação que o desenvolvimento de uma cultura de si se faz imprescindível. Nesse sentido, o artefato analisado acaba, indiretamente, contribuindo para o desenvolvimento da identidade das infâncias leitoras do livro, a partir da conscientização da igualdade racial e da aceitação de sua identidade étnico/estético-cultural. Além disso, propicia um fortalecimento do sujeito frente a forças de poder que intentam o governar para algo contrário. Nesse sentido, Foucault (2009b) afirma: "A força do poder não é independente de qualquer coisa como a manifestação do verdadeiro entendido para além disso que é simplesmente útil e necessário para bem governar." (FOUCAULT, 2009b, p.16). Dessa forma, fortalecer a identidade das infâncias leitoras desta obra podem vir a prepara-las para o governo contrário, reforçando também uma cultura de si. 


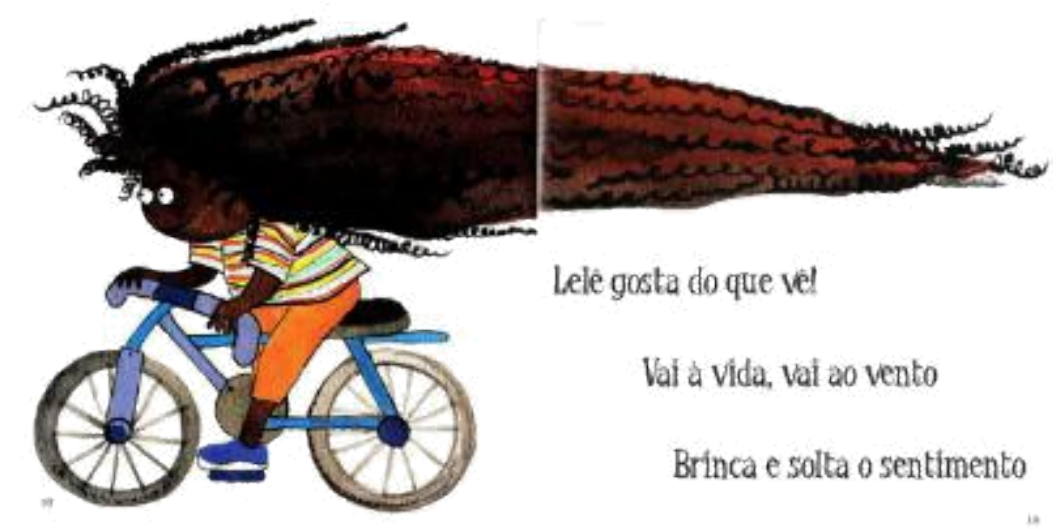

Imagens 12 e 13 - Lelê satisfeito com sua identidade étnico/estético-cultural.

\section{Visões da infância: o matrimônio}

A partir das necessidades sociais atuais, as pedagogias têm buscado constante atualização para, conforme posto por Camozzato e Costa (2013), dar conta de significar as diversas esferas de nossas vidas, e dessa forma atuar nos discursos que buscam constituir as identidades. Ainda conforme os autores citados, “[...] há a vontade de pedagogia, posto que há vontade de conduzir sujeitos, que há vontade de governar." (CAMOZZATO; COSTA, 2013, p. 23). Assim, uma vez que a obra analisada busca propor formas de governamento a partir da construção de identidades visando à aceitação de uma constituição étnico/estético-cultural.

Porém, ao tomarmos opção por uma pedagogia, deixamos abertas outras várias pedagogias, inclusive antagônicas e que estão em luta por hegemonia em relação às vivenciadas . Em outras palavras, segundo Camozzato e Costa (2013), “[...] nesta seara da vida, uma vigorosa vontade de pedagogia se manifesta e forja mais pedagogias." (p.39). No que tange a obra analisada, ao propor formas de governamento pela (re)afirmação de identidades étnico/estético-culturais, possibilita-se ainda a reflexão sobre a erotização infantil posta na obra através da lógica matrimonial demonstrada.

$\mathrm{Na}$ história, Lelê passa a compreender sua identidade e aceitar-se esteticamente, o que atrai os olhares de um menino que se encanta por ela e passa, ainda que infimamente, a namorá-la. Felipe e Guizzo (2003) afirmam que com o crescimento e a passagem da infância, o fluxo normal é que brinquedos e brincadeiras sejam deixados de lado, e passe a aflorar interesses por namoros e a descoberta pela sexualidade. Na obra, o cabelo é visto como objeto de sedução utilizado por Lelê, ficando claro na frase "O negro Cabelo é pura magia". E se antes as imagens retravam o personagem brincando, infantilizado e com roupagens unissex (deixando no ar a real identidade de gênero do personagem), agora o 
mostram com referências ao matrimônio, vestida como menina e inclusive demonstrando um beijo entre Lelê e o menino que agora se apresenta como seu namorado.

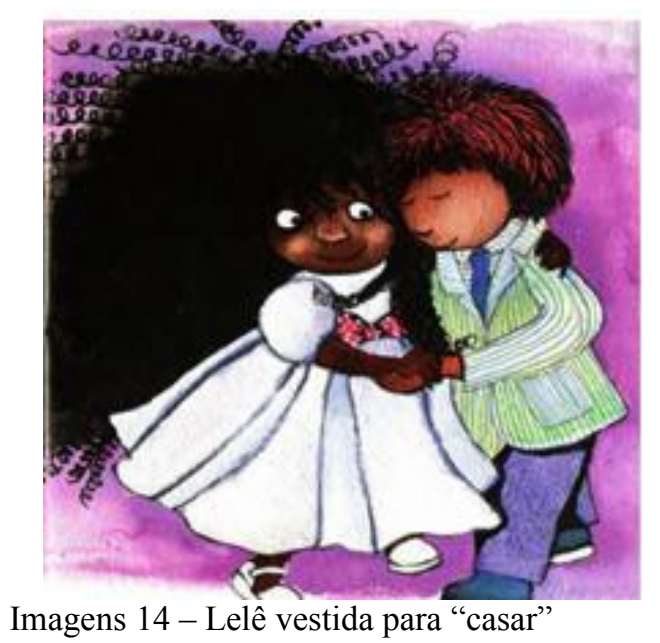

A partir da representação da personagem com um vestido branco, pode-se fazer referência à lógica matrimonial, tirando da infância o governamento de si, através de uma indução ao casamento nas imagens retratadas. Foucault (2009a) afirma que a partir do reconhecimento de si como membro de uma comunidade e como ser humano, o casamento se apresenta como dever e forma de manutenção de valor entre esta comunidade. Assim, a partir do conhecimento de suas raízes e reconhecimento de sua identidade, apresenta-se Lelê como implicada a casar-se para ser um membro de valor e fazer parte de uma comunidade. Saffioti (1987) afirma que devido a intervenções sociais do homem, torna-se impossível separar o que é natural daquilo que foi naturalizado. Isso porque ainda segundo a mesma autora, a sociedade tem investido muito na naturalização de alguns processos sociais. Assim, o artefato aqui analisado pode constituir-se como uma estratégia que acaba por naturalizar o matrimonio e não o apresentar como processo social de escolha de seus participantes.

Com as mudanças na sociedade, desenvolvem-se novas relações e novas formas de manutenção dessas relações, tanto para com os outros quanto para si mesmo. A partir desse contexto, é normal que as relações (incluídas aí as matrimoniais) se alterem, uma vez que se acentuam novas formas de gostar, querer, desejar, ser e identificar-se. Dessa forma, a representação do matrimonio tida ainda conforme posto por Bittar (2007) como "casamento-amor", encontra-se tons de infantilidade, visando suavizar o papel matrimonial. Assim, os personagens são retratados com feições carinhosas e felizes, idealizando a lógica do matrimônio e colocando-a como processo natural (inclusive na infância). 


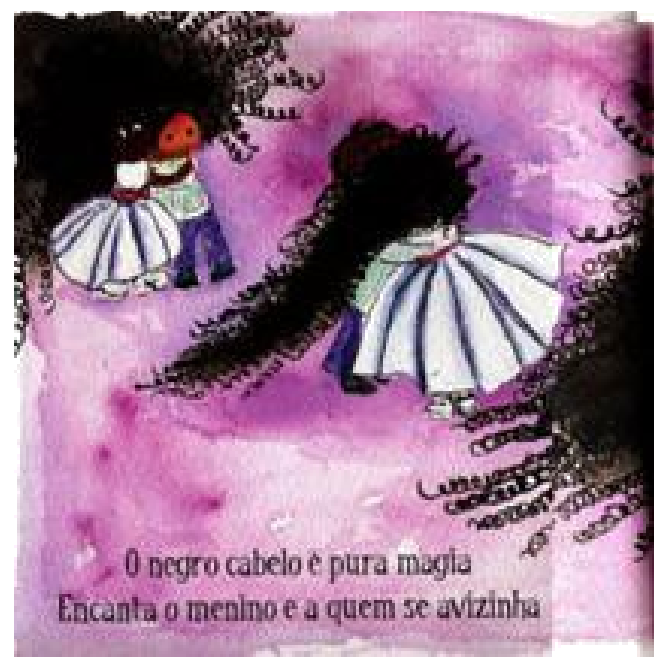

Imagem 15 - Lelê e o "rito matrimonial"

Em outro ponto, cabe ressaltar ainda a feminilização do personagem a partir do encontro de seu "namorado". Lelê era retratada durante toda a obra com uma roupagem unissex, infantilizada e sem uma aura de sensualidade. Porém, a partir do seu encontro com o sexo oposto, a personagem passa a vestir de forma diferente e ter feições mais adultas, buscando uma feminilidade que não havia sido mostrada ainda. A partir das palavras de Guizo e Beck (2011), percebe-se que em nossa sociedade, é normal a apresentação das mulheres como seres belos e dotados de sensualidade, e por isso evidencia-se um cuidado maior com o corpo, as roupas e suas feições. Essa situação evidencia-se conforme posto por Saffioti (1987) quando se fala de mulheres negras:

Retomando o caso da mulher negra, cabe salientar que o homem branco construiu o mito da negra ou mulata sensual. Embora nenhuma pesquisa haja demonstrado que a negra ou a mulata seja mais sensual do que a branca, e assim que a mulher de sangue negro e socialmente considerada. Interessa ao homem branco alimentar este mito, pois, por tradição, está habituado a "usar sexualmente" negras ou mulatas. (SAFFIOTI, 1987, p.53)

O personagem principal somente após conhecer, reconhecer e aceitar sua identidade inicia um processo de erotização. Em seu trabalho, Furlani (2005) afirma que ao delimitar os sujeitos trabalhados e ainda a forma como serão apresentados, os artefatos culturais estabelecem graus de hierarquia a serem seguidos, segmentando assim as identidades desses sujeitos. Inicialmente, cabe referir-se aqui ao conceito de sexualidade a partir de Foucault (1999), a ser trabalhado doravante: “[...] é o conjunto de efeitos produzidos nos corpos, nos comportamentos, nas relações sociais, por um certo dispositivo pertencente a 
uma tecnologia política complexa" (FOUCAULT, 1999, p.120). Partindo ainda de Foucault, percebe-se que os mecanismos de interdição do sexo agem no artefato deixando porém uma necessidade de confissão inconsciente latente:

O indivíduo, durante muito tempo, foi autenticado pela referência dos outros e pela manifestação de seu vínculo com outrem (família, lealdade, proteção); posteriormente passou a ser autenticado pelo discurso de verdade que era capaz de (ou obrigado) ter sobre si mesmo. A confissão da verdade se inscreveu no cerne dos procedimentos de individualização pelo poder. (FOUCAULT, 1999, p.67)

Em outras palavras, cria-se a ideia de interdição da sexualidade com a finalidade de agir sobre ela. Ao passo que as infâncias são conduzidas a pensar em matrimônio e em amor juvenil, a lógica sexual e erótica fica em segundo plano, imbricada nos discursos da obra. De modo similar Foucault (1999) remete ao pensamento da sexualidade como constitutiva das relações de poder. Entendendo aqui poder como:

Multiplicidade de correlações de força imanentes ao domínio onde se exercem e constitutivas de sua organização; o jogo que, através de lutas e afrontamentos incessantes as transforma, reforça, inverte, os apoios que tais correlações de força encontram umas nas outras, formando cadeias ou sistemas ou ao contrário, as defasagens e contradições que as isolam entre si; enfim, as estratégias em que se originam e cujo esforço geral ou cristalização institucional toma corpo nos aparelhos estatais, na formulação de Leis, nas hegemonias sociais (FOUCAULT, 1999, p.8889).

Como foi colocado, o conjunto de forças age sobre as infâncias a partir de sua sexualidade, e na obra analisada, mais especificamente, atua para seu governamento, visto que onde há o interesse de educar, há o interesse de governar, conforme já mencionado anteriormente.

Para finalizar, ao buscar agir sobre a infância negra, o presente artefato corrobora também para a educação nos atos machistas (mulher como ser puro e objeto de sensualização) e para a erotização das infâncias, a partir da personagem Lelê, indo assim na contramão do pressuposto de educação proposto pela obra, de conscientizar e levar as infâncias a conhecerem e reconhecerem suas raízes, visando promover uma ideia de promoção da igualdade racial.

\section{Considerações Finais}

O estudo realizado buscou contribuir para reflexões sobre os desígnios educativos provenientes do artefato cultural posto em debate, considerando ao mesmo passo que 
Camozzato e Costa (2013), a educação como "[...] uma forma incessante de fazer perpetuar modos de vida e fazer com que os saberes se perpetuem." ( p.26). A partir desta concepção, buscou-se, também, pensar na forma como esse artefato contribui para a constituição das identidades das infâncias negras a partir de interpretações e análises sobre o tema. Além disso, ao pensar a busca de representação das infâncias em busca (ou em construção) de sua identidade étnico/estético-cultural, este artefato apresenta-se como produto de circulação cultural de saberes, e justamente por possuir esta característica deve ser analisado e interpretado, para que assim como posto por Camozzato (2015), se possa considerar também uma "pedagogia interprete" e assim atuar da melhor maneira na educação de sujeitos. Além disso, Foucault (2009b) em uma de suas aulas em seu curso no Collège de France, ressalta: "numa palavra, como poder-se-ia governar sem conhecer isso que se governa, sem conhecer esses a quem se governa e sem conhecer o meio de governar esses homens e essas coisas?” (FOUCAULT, 2009b, p.09). Dessa forma inicialmente existe a necessidade de se conhecer as infâncias a serem estudadas, e doravante, também os artefatos que ajudam a governar esses sujeitos.

Em outro ponto, objetivou-se analisar a imagem da erotização infantil a partir da representação do matrimonio que abarcou os personagens do livro. Nesse sentido, Louro (2003) contribui ao afirmar que “[...] não cabe perguntar se uma representação 'corresponde' ou não ao 'real', mas, ao invés disso, como as representações produzem sentidos, quais seus efeitos sobre os sujeitos, como elas constroem o 'real' (LOURO, 2003, p. 99). Salienta-se a reflexão para a interpretação desses processos, visando o reconhecimento dos processos em que atua para que assim a educação possa acompanhar as mudanças da sociedade e assim agir e atuar sobre ela.

Por fim, cabe refletir sobre como essa crescente vontade de pedagogia pode contribuir para a produção de sujeitos que possam refletir e interagir sobre os mais diversos ambientes, culturas e sociedades. Uma vez que com a liquidificação das identidades, se torna mais difícil o delineamento de uma estratégia única de condução, a pluralização de pedagogias pode contribuir para esse contexto. Porém, chama-se atenção ainda para o fato de que essa vontade de educar pode refletir também em uma "deseducação". Nesse caso, conforme exposto por Camozzato e Costa (2013), o que se põe em frente ao debate é o tipo de sujeito a ser formado. Para cada tipo de sujeito, existem estratégias para o educar, utilizando-se de saberes vistos como importantes nesse processo, buscando a produção de sujeitos com os saberes necessários para interagir e viver em conjunto em sociedade. 
$\mathrm{O}$ artefato analisado, ainda que implicitamente, demonstrou as características do sujeito a ser delineado a partir de sua influência. Nesse sentido, o livro exalta a busca pelas identidades, valorizando assim sua cultura étnico/estético. Porém, em sua composição, o artefato acaba por desenvolver ideias para promover uma espécie de erotização infantil através do matrimonio, colocando a mulher negra como objeto sensualizado mesmo na infância. Para finalizar, cabe ressaltar a importância do estudo dos artefatos culturais, bem como suas estratégias de educação para a infância e para o desenvolvimento de uma cultura de si, principalmente na infância.

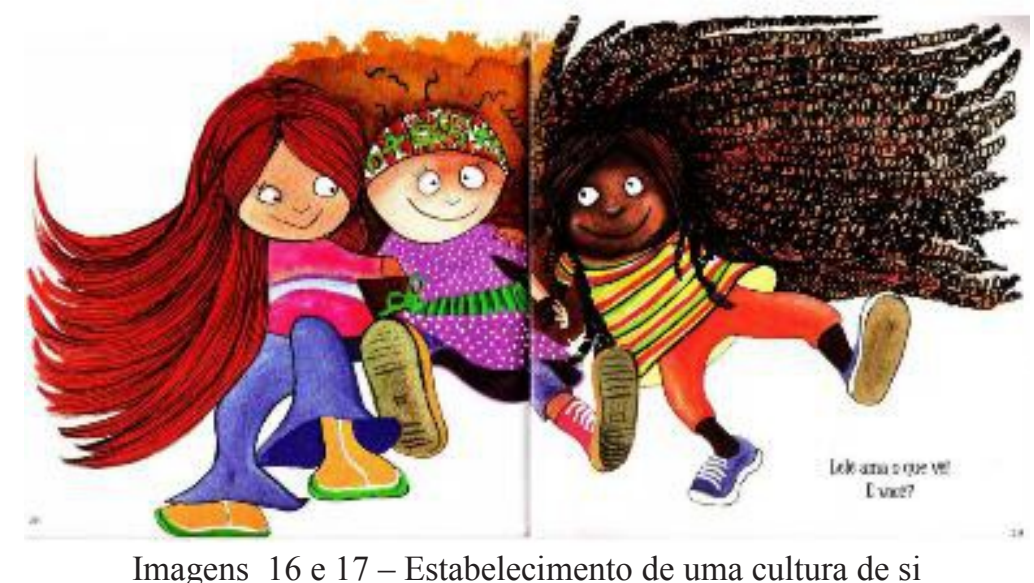

Imagens 16 e 17 - Estabelecimento de uma cultura de si

Por fim, a guisa de conclusão acreditamos com este trabalho ter possibilitado uma nova compreensão na forma de percepção dos livros infantis como artefatos culturais de grande importância para o governo da infância, explicitando uma vontade de pedagogia própria voltada principalmente para as relações étnico-raciais, porém atuando também nas relações de gênero.

\section{Referências}

BAMBI, Lisete. Governo, subjetivação e resistência em Foucault. Educação \& Realidade, Porto Alegre, v. 27, n. 1, p. 127-150, jan./jun. 2012.

BITTAR, Eduardo Carlos Bianca. Família, sociedade e educação: um ensaio sobre individualismo, amor líquido e cultura pós-moderna. Revista da Faculdade de Direito da Universidade de São Paulo, São Paulo, v. 102, p. 591-610, jan/dez. 2007.

CAMOZZATO, Viviane Castro. Entre a pedagogia legisladora e as pedagogias intérpretes. Revista Brasileira de Educação, Rio de Janeiro, v. 20 n.61, p. 501-5017, abr/jun, 2014. 
Pedagogias do Presente. Educação \& Realidade, Porto Alegre, v. 39, n. 2, p. 573-593, abr./jun. 2014.

CAMOZZATO, Viviane Castro; COSTA, Marisa Vorraber. Vontade de pedagogia pluralização das pedagogias e condução dos sujeitos. Cadernos de Educação Faculdade de Educação - UFPEL, Pelotas, n. 44, p. 22-44, jan./abr. 2013.

COSTA, Marisa Vorraber. Sobre as contribuições das análises culturais para a formação dos professores do início do século XXI. Educar, Curitiba, n.37, p. 129-152, maio/ago, 2010.

; SILVEIRA, Rosa Hessel; SOMMER, Luis Henrique. Estudos culturais, educação e pedagogia. Revista Brasileira de Educação, Rio de Janeiro, n.23, p. 36-61, maio/ago, 2003.

EAGLETON, Terry. A ideia de cultura. Tradução: Sofia Rodrigues. Lisboa: Temas e Debates - Actividades Editoriais, 2000.

LIMA JUNIOR, Agnaldo Mesquita de; FREITAS, Santiago Bretanha. Um grito de negritude: Experiências na formação de leitores/escritores no Programa Mais Educação. Conexões Culturais, Jaguarão, v. 1 n. 02, p. 12-20, 2015.

LOURO, Guacira Lopes. Gênero, sexualidade e educação: uma perspectiva pósestruturalista. 6. Ed. Petrópolis: Vozes, 2003.

FELIPE, Jane; GUIZZO, Bianca Salazar. Erotização dos corpos infantis na sociedade de consumo. Pro-posições, Campinas, v. 14, n. 3(42), p. 119-130, set/dez. 2003.

FISCHER, Rosa Maria Bueno. Foucault e a análise do discurso em educação. Cadernos de Pesquisa, São Paulo, n. 114, p.197-223, nov. 2001.

FOUCAULT, Michel. O sujeito e o poder. In: DREYFUS, H. L. \& RABINOW, P. Michel Foucault: Uma trajetória filosófica: para além do estruturalismo e da hermenêutica. Rio de Janeiro: Forense Universitária, 1995. p.231-249.

História da sexualidade I: a vontade de saber. 13. Ed. Rio de Janeiro: Graal, 1999.

. Microfísica do Poder. 17. Ed. Rio de Janeiro: Graal, 2002.

Arqueologia do Saber. 7. Ed. Rio de Janeiro: Forense, 2008.

História da sexualidade III: o cuidado de si. 10. Ed. São Paulo: Graal, 2009a.

Do governo dos vivos: Curso no Collège de France, 1979-1980: aulas de 09 e 30 de janeiro de 1980. tradução, transcrição e notas Nildo Avelino. - São Paulo: Centro de Cultura Social, 2009b. 
FURLANI, Jimena. O bicho vai pegar! - Um olhar pós-estruturalista à educação sexual a partir de livros paradidáticos infantis. 2005, 197f. (Doutorado em Educação) Universidade Federal do Rio Grande do Sul - UFRGS. Porto Alegre, RS. 2005. [Online].

GUIZZO, Bianca Salazar; BECK, Dinah Quesada. Corpo, Gênero, erotização e embelezamento na infância. Textura, Canoas, n. 24, p. 16-36 jul/dez. 2011.

GOUVÊA, Maria Cristina Soares. Imagens do negro na literatura infantil brasileira: análise historiográfica. Educação e Pesquisa, São Paulo, v.31, n.1, p. 77-89, jan./abr. 2005.

ICLE, Gilberto. Pedagogia teatral como cuidado de si : problematizações na companhia de Foucault e Stanislavski. In: 30ª Reunião Anual da Anped, 2007, Caxambu, PR. CDROM. p. 1-16

NYAMIEN, Francy Rodrigues da Guia. Educação e identidade étnico-racial. In: $1^{\circ}$ Simpósio Nacional de Educação; XX Semana da Pedagogia, 2008, Cascavel, PR. Anais. p. $1-15$.

PRUDENTE, Celso Luiz. A dimensão pedagógica do cinema negro e a construção da imagem afirmativa positiva do ibero-ásio-afro-ameríndio: pontos à compreensão da identidade da pessoa em condição de rua. In: FÁVERO, Altair Alberto; TAUCHEN, Gionara. Políticas de Educação Superior: diálogos sul-sul. Curitiba, PR: CRV, 2016.

SAFFIOTI, Heleieth Iara Bongiovani. O poder do macho. São Paulo: Moderna, 1987. WESCHENFELDER, Viviane Inês. A produção do sujeito negro: uma analítica das verdades que circulam em Venâncio Aires - RS. 2012, 172f. Dissertação (Mestrado em Educação) - Universidade do Vale do Rio dos Sinos - UNISINOS. São Leopoldo. 2012. [Online]. 